\title{
Macrophages Are Eliminated from the Injured Peripheral Nerve via Local Apoptosis and Circulation to Regional Lymph Nodes and the Spleen
}

\author{
Tanja Kuhlmann, ${ }^{1}$ Andreas Bitsch, ${ }^{2}$ Christine Stadelmann, ${ }^{1}$ Heike Siebert, ${ }^{1}$ and Wolfgang Brück ${ }^{1}$ \\ ${ }^{1}$ Department of Neuropathology, Charité, Campus Virchow-Klinikum, 13353 Berlin, Germany, and 2Department of \\ Neurology, University of Göttingen, 37075 Göttingen, Germany
}

The present study investigated the fate of macrophages in peripheral nerves undergoing Wallerian degeneration, especially their disappearance from the injured nerves after phagocytosis of axonal and myelin debris. Wallerian degeneration was induced in adult male $\mathrm{C} 57 \mathrm{BI} / 6$ mice by transecting the right sciatic nerve. Five days after transection, the male sciatic nerves were transplanted into female recipient mice by placing them exactly parallel to the host sciatic nerves. Nerves of the female recipient mice were also transected to induce breakdown of the blood-nerve barrier in the host animal. Apoptosis was assessed by morphological, immunohistochemical (activated caspase-3), and molecular (DNA fragmentation) methods in transplanted, recipient, and in control nerves. A subpopulation of macrophages within the degenerating nerves died locally by apoptosis in each experiment. The fate of the male macrophages within the transplanted nerves and the host organism was investigated by in situ hybridization with a Y-chromosome-specific DNA probe (145SC5). In situ hybridization specifically stained cells within the transplanted male nerve. Y-chromosome-positive cells were detected not only inside the transplanted nerve, but also inside the female host nerve, the perineurial tissue, the local perineurial blood vessels, draining lymph nodes and the spleen of the female host, suggesting hematogenous as well as lymphatic elimination of macrophages from the injured nerve. These data indicate that local apoptosis and systemic elimination via circulation to the local lymph nodes and the spleen are involved in the disappearance of macrophages from the injured peripheral nervous system.

Key words: macrophage; elimination; nervous system; apoptosis; migration; Y-chromosome probe; transplantation
The mechanisms that affect and regulate macrophage infiltration of peripheral nerves during Wallerian degeneration have extensively been investigated in recent years (Stoll and Hartung, 1992; Griffin and Hoffman, 1993; Brück, 1997). Disconnection of the axon through traumatic, toxic, degenerative, ischemic, or metabolic damage leads to calcium-dependent axonal degeneration, retraction of Schwann cell cytoplasm from myelin sheaths, and formation of myelin ovoids within the first $24 \mathrm{hr}$ (Beuche and Friede, 1984; Griffin and Hoffman, 1993; George et al., 1995). These events are followed by intense Schwann cell proliferation and recruitment of hematogenous and resident macrophages, which remove the degenerated myelin (Stoll et al., 1989; Fernandez-Valle et al., 1995; Brück et al., 1996a; Brück, 1997). Factors of axonal origin, complement components, adhesion molecules, and degenerating myelin itself attract macrophages to migrate into transected nerves (Brück and Friede, 1990, 1991; Griffin et al., 1992; Brück et al., 1995; Brown et al., 1997; Vougioukas et al., 1998).

So far, no studies have been published that investigate the mechanisms or pathways leading to the disappearance of macrophages from the damaged peripheral nerves. From other experimental models of tissue injury such as experimental autoimmune

Received Aug. 10, 2000; revised Feb. 15, 2001; accepted Feb. 23, 2001.

Antiserum against activated caspase- 3 was kindly provided by T. L. Deckwerth and Anu Srinivasan. We thank Brigitte Maruschak and Stephanie Bunkowski for excellent technical assistance.

Correspondence should be addressed to Dr. Wolfgang Brück, Department of Neuropathology, Charité, Campus Virchow-Klinikum, Augustenburger Platz 1, 13353 Berlin, Germany. E-mail: wolfgang.brueck@charite.de.

Copyright (C) 2001 Society for Neuroscience 0270-6474/01/213401-08\$15.00/0 encephalomyelitis (EAE) or myocardial infarction it is known that local apoptosis is involved in the elimination of infiltrating inflammatory cells (Nguyen et al., 1994, 1997; Smith et al., 1996; Takemura et al., 1998). Immunologically, the elimination of macrophages has been described as macrophage disappearance reaction; it is observed during delayed type hypersensitivity reactions and can be inhibited or induced by various stimuli (Barth et al., 1995).

The purpose of the present study was to clarify the mechanisms by which macrophages are eliminated from the injured peripheral nerve tissue. The following two hypotheses were tested: (1) macrophages are eliminated by local apoptosis or (2) macrophages migrate to local lymph nodes and the spleen. For these experiments, transected male sciatic nerves undergoing Wallerian degeneration were transplanted into female mice. The transplanted nerves were massively laden with macrophages and placed side-by-side to the host sciatic nerve, which was also transected. Apoptotic cells within the degenerating nerves were identified by morphologic criteria, DNA fragmentation (Brück et al., 1996b), and the antibody CM-1, which recognizes the large subunit of caspase-3 generated after activation (Srinivasan et al., 1998; Stadelmann et al., 1999). Activation of caspase-3 takes place in the effector phase of the apoptotic process, and its detection therefore represents a reliable tool for the identification of apoptotic cells. Transplanted macrophages were followed by in situ hybridization with a Y-chromosome-specific probe (Singh et al., 1987; Grounds et al., 1991).

\section{MATERIALS AND METHODS}

Animal surgery and transplantation. All animal surgery was done in accordance with the German guidelines for animal experiments and was 
officially approved by the county government of Braunschweig (Germany). Wallerian degeneration was induced in 15 adult male and two female C57Bl/6 mice by transecting the right sciatic nerve under deep anesthesia with Ketanest $(50 \mathrm{mg} / \mathrm{ml}$; Parke-Davis, Courbevoie, France; $0.6 \mathrm{mg} / 10$ gm body weight) and Rompun (2\%; Bayer; $23.5 \mu \mathrm{l} / 10 \mathrm{gm}$ body weight). The animals were decapitated under deep anesthesia $5 \mathrm{~d}$ after nerve transection. A uniform 5-mm-long piece of the degenerated sciatic nerve was immediately explanted and transplanted into 15 female or two male $\mathrm{C} 57 \mathrm{Bl} / 6$ mice, respectively. The transplanted nerves were placed sideby-side to the host sciatic nerve, which was also transected to induce breakdown of the blood-nerve barrier. The transection sites of both the transplanted and the recipient nerve were aligned and fixed by a muscle suture. On days after transplantation (DPT) 2, 5, 10, 20, and 40, corresponding to days $7,10,15$, etc. after transection, the mice were perfused under deep anesthesia through the left cardiac ventricle with PBS followed by $4 \%$ paraformaldehyde. Each experimental group consisted of three animals. Degenerating host and donor sciatic nerves, the contralateral nontransected host sciatic nerve, regional and para-aortal lymph nodes, as well as the spleen were removed from each animal, post-fixed in $4 \%$ paraformaldehyde, and embedded in paraffin wax. Additionally, three control animals were used in which transected sciatic nerves were allowed to degenerate for $6 \mathrm{~d}$ in situ in the absence of any transplantation procedure to control for effects of nerve transplantation on cell invasion or macrophage apoptosis. The $5-\mu \mathrm{m}$-thick sections of all tissues were stained with hematoxylin-eosin (H\&E).

Immunohistochemistry. Immunohistochemistry was performed by using an avidin-biotin complex (ABC) technique on serial sections from the transected donor and host nerves. After deparaffinization, intrinsic peroxidase activity was blocked by incubation with $5 \% \mathrm{H}_{2} \mathrm{O}_{2}$ in PBS for 20 min. Nonspecific antibody binding was inhibited with $10 \%$ fetal calf serum (FCS) in PBS for $25 \mathrm{~min}$. The sections were stained with monoclonal antibodies against the macrophage antigens F4/80 (160 kDa glycoprotein; Serotec, Oxford, UK) and Mac-3 (PharMingen, San Diego, CA) at a dilution of 1:50 and 1:200, respectively. For further immunocytochemical staining we used polyclonal antisera or monoclonal antibodies directed against T cells (CD3; Serotec; dilution 1:400), the S-100 antigen (Dako, Glostrup, Denmark; dilution 1: 50) and activated caspase-3 (CM-1; kindly provided by T. L. Deckwerth and A. Srinivasan, Idun Pharmaceuticals, La Jolla, CA; dilution 1:5000). The CM-1 antibody is specific for the large subunit of caspase-3 and thus for the activated enzyme (Srinivasan et al., 1998). The slides were incubated overnight at $4^{\circ} \mathrm{C}$. Microwave pretreatment (five times for $3 \mathrm{~min}$ at $800 \mathrm{~W}$ ) was applied for the CD3, Mac-3, and CM-1 antibodies. Secondary antibodies were biotinylated anti-rat or anti-rabbit Ig (Dako) applied at a dilution of 1:200 for $60 \mathrm{~min}$ followed by incubation with the ABC complex (Vector Laboratories, Burlingame, CA) for $1 \mathrm{hr}$ using diaminobenzidine (DAB) as chromogen. The primary antibody was omitted in control sections.

For double immunohistochemistry immunofluorescence procedures were used. The binding of the primary antibodies (CM-1, Mac-3) was visualized using Oregon green (Mobitec)- or Cy3 (Jackson ImmunoResearch, West Grove, PA)-coupled secondary reagents. The slides were examined on a Zeiss confocal laser-scanning microscope (LSM 510).

Semithin sections. Two C57Bl/6 mice were decapitated under deep anesthesia $10 \mathrm{~d}$ after transection of the right sciatic nerve. The distal nerve stumps were removed and immediately fixed in $2.5 \%$ glutaraldehyde and post-fixed in $1 \%$ osmium tetroxide. Specimens were dehydrated in graded concentrations of alcohol, passed through propylene oxide, and embedded in Araldite. Semithin sections $(1 \mu \mathrm{m})$ were stained with Richardson's staining solution (1\% Azur II, 2\% Methyleneblue, 1\% Borax).

In situ tailing. The in situ tailing technique (IST) was performed as described in detail elsewhere (Gold et al., 1993). Sections were deparaffinized and then incubated for $1 \mathrm{hr}$ at $37^{\circ} \mathrm{C}$ in a reaction mix containing $10 \mu \mathrm{l}$ of $5 \times$ tailing buffer, $2 \mu \mathrm{l}$ of cobalt chloride, $1 \mu \mathrm{l}$ of digoxigenin labeling mixture (nucleotides), and $6 \mathrm{U}$ of terminal transferase. Distilled water was added to give a total volume of $50 \mu \mathrm{l}$. Sections were washed in TBS, followed by incubation with alkaline phosphatase-labeled antidigoxigenin antibody (diluted 1:250 in distilled water containing 10\% FCS) for $1 \mathrm{hr}$ at room temperature. The color reaction was developed with nitroblue tetrazolium (NBT) and 5-bromo-4-chloro-3-indolylphosphate (BCIP). All reagents, enzymes, and antibodies were purchased from Boehringer Mannheim (Mannheim, Germany). IST-positive macrophages were detected by double immunohistochemistry with the antibody F4/80 as described above.
Probe synthesis and in situ hybridization. A DNA probe specific for the mouse Y-chromosome was generated by PCR. A $722 \mathrm{bp}$ fragment of the mouse Y-chromosome was amplified from a plasmid containing a $1.5 \mathrm{~kb}$ sequence of the 145SC5 mouse Y-chromosome (a generous gift of L. Singh) (Singh et al., 1994). The PCR reaction mixture consisted of $40 \mathrm{ng}$ of DNA, $5 \mu \mathrm{l}$ of $10 \times$ buffer, $1.5 \mathrm{~mm} \mathrm{MgCl}, 5 \mu \mathrm{l}$ of PCR DIG Probe Synthesis Mix (2 mm dATP, dCTP, dGTP, $1.3 \mathrm{~mm}$ dTTP, and $0.7 \mathrm{~mm}$ DIG-11-dUTP), $2.5 \mu \mathrm{l}$ of each primer $(10 \mathrm{pmol} / \mu \mathrm{l})$ (forward primer: 5'-GTG TCT GGT GTA AAC GGG CA; reverse primer: 5'-ACT TTT TGG ATC CAT CAT CTC T) and $2.5 \mathrm{U}$ of polymerase mixture (Expand High Fidelity PCR System) in a total volume of $50 \mu$ l. All reagents were purchased from Boehringer Mannheim. The PCR profile consisted of 35 cycles of denaturation at $94^{\circ} \mathrm{C}$ for $1 \mathrm{~min}$, annealing at $55^{\circ} \mathrm{C}$ for $30 \mathrm{sec}$ and an extension at $72^{\circ} \mathrm{C}$ for $1 \mathrm{~min}$. An initial denaturation step for $5 \mathrm{~min}$ and a prolonged extension step at $72^{\circ} \mathrm{C}$ for $10 \mathrm{~min}$ after the last cycle completed the PCR program. The amplification product was transferred to a $1 \%$ agarose gel. After electrophoresis the specific band was cut and purified by the Qiagen (Hilden, Germany) Extraction kit according to the manufacturer's protocol.

Nonradioactive in situ hybridization was performed as described earlier (Breitschopf et al., 1992). Slides were dewaxed in xylene and rehydrated. Proteinase $\mathrm{K}$ digestion $(50 \mu \mathrm{g} / \mathrm{ml})$ was performed at $37^{\circ} \mathrm{C}$ for 20 min. Sections were dehydrated in graded alcohol and chloroform. The hybridization mix was denatured in boiling water for $10 \mathrm{~min}$ and consisted of $5 \times$ SSC, $5 \%$ dextran sulfate, $0.01 \%$ salmon sperm DNA, $0.02 \%$ SDS, and the probe at a concentration of $0.2 \%$. The slides with the hybridization mix were denatured for $5 \mathrm{~min}$ at $95^{\circ} \mathrm{C}$. Hybridization was performed at $42^{\circ} \mathrm{C}$ for $12-16 \mathrm{hr}$. Sections were washed in $1 \times$ and $2 \times \mathrm{SSC}$ at $37^{\circ} \mathrm{C}$ for $30 \mathrm{~min}$ each. Nonspecific antibody binding was prevented by incubation in Boehringer's blocking reagent with $10 \%$ FCS for 15 min. An anti-digoxigenin antibody conjugated to alkaline phosphatase (Boehringer Mannheim) was used at a dilution of 1:250 for 2-3 hr. The reaction product was visualized with NBT-BCIP. The signal was developed between 4 and $8 \mathrm{hr}$. As positive and negative controls, male and female mouse brain tissue was included in each in situ hybridization.

Southern blot. A Southern blot was performed to control the specificity of the probe, in addition to the positive and negative controls for in situ hybridization. It is known that Y-chromosome probes may also recognize female DNA sequences (Shinohara et al., 1995) or may be strainspecific (Grounds et al., 1991). Genomic DNA was extracted from male and female mouse tails by using the Qiagen DNA Extraction kit according to the manufacturer's protocol. Five micrograms of DNA were digested with EcoRI and electrophoresed in a $1 \%$ agarose gel. DNA fragments were transferred to a positively charged nylon membrane (Sambrook et al., 1989). The filter was prehybridized with a mixture consisting of $50 \%$ formamide, $0.1 \% \mathrm{~N}$-laurylsarcosine, $0.02 \%$ SDS, and $2 \%$ Boehringer blocking reagent for $2-3 \mathrm{hr}$ at $42^{\circ} \mathrm{C}$. The prehybridization mixture was discarded and replaced by a hybridization solution containing the same components as the prehybridization mixture, including the DIG-labeled probe. The incubation was continued for $16 \mathrm{hr}$. The filter was washed twice in $2 \times$ SSC and $0.1 \%$ SDS for 5 min at room temperature as well as twice in $0.5 \times \mathrm{SSC}$ and $0.1 \%$ SDS for $15 \mathrm{~min}$ at $68^{\circ} \mathrm{C}$. To prevent nonspecific antibody binding, the filter was incubated in Boehringer blocking reagent for $60 \mathrm{~min}$. The filter was incubated with an anti-digoxigenin antibody conjugated to alkaline phosphatase (Boehringer Mannheim) at a dilution of 1:5000 for $30 \mathrm{~min}$. The filter was washed twice in $0.1 \mathrm{M}$ maleic acid, $0.1 \mathrm{M} \mathrm{NaCl}$, and $0.3 \%$ Tween 20 . The signal was visualized with NBT-BCIP. A strong signal of $1.5 \mathrm{~kb}$ in the male (but not in the female) mouse DNA demonstrated the specificity of the probe used (Fig. 1). Hybridization with a probe for prion protein gene $(2.2 \mathrm{~kb})$ served as control for equal DNA content of the samples.

Morphometry and statistics. The numbers of Mac-3- or F4/80-positive macrophages were counted per square millimeter of degenerating nerve tissue in the transplanted and recipient nerves as well as in the transected nerves of the control animals. A standardized microscopic field of 10,000 $\mu \mathrm{m}^{2}$ was defined by an ocular morphometric grid at a final magnification of $1000 \times$. Values represent numbers of stained cells per square millimeter $($ mean $\pm \mathrm{SD})$ per entire cross-section area of the nerves. The same procedure was used to determine the numbers of cells with apoptotic morphology stained in H\&E sections, Mac-3-positive apoptotic cells, IST-positive cells, and CM-1-positive cells. The number of Y-chromosomepositive cells was determined semiquantitatively in the transplanted and recipient nerves, the perineurial tissue, the regional and para-aortal lymph nodes, as well as the spleen according to the following scheme: -, no positive cells;,$+ 1-4$ positive cells;,$++ 5-10$ positive cells;,$+++>10$ 


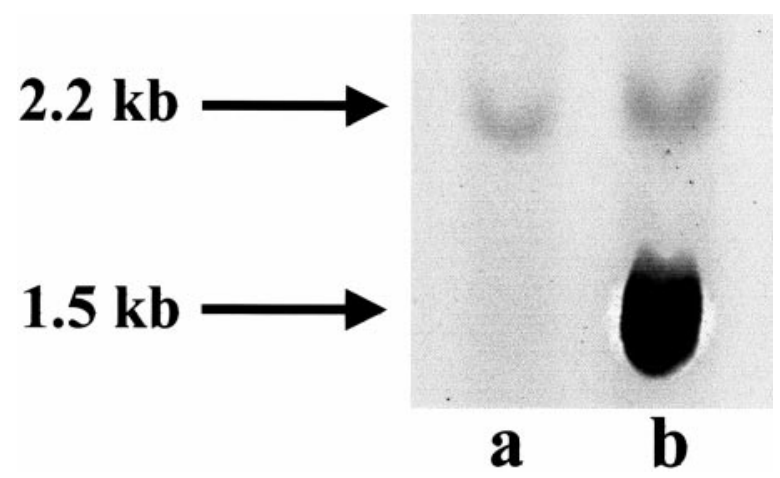

Figure 1. Southern blot. Five micrograms of DNA extracted from female (a) and male $(b)$ tissue were digested with EcoRI, electrophoresed in agarose gel (1\%), blotted on a nylon membrane, and hybridized with the 145SC5 probe, which detected a strong signal of $1.5 \mathrm{~kb}$ in the male DNA. The $2.2 \mathrm{~kb}$ band detected by hybridization with a probe for the prion protein gene demonstrates similar amounts of DNA on each lane.

positive cells. The Mann-Whitney $U$ test and the ANOVA test were used for statistical analysis. A $p$ value $<0.05$ was considered significant.

\section{RESULTS}

\section{Morphology of the transected transplant and recipient nerves}

Wallerian degeneration induces recruitment of monocytes from the circulation into the damaged nerves. Earlier experiments showed that this invasion takes place within the first $2-4 \mathrm{~d}$ after nerve transection (Brück, 1997). Accordingly at all times, the transplanted and the transected recipient, as well as the control nerves, were infiltrated by numerous macrophages. The phagocytes were found inside the endoneurial space as well as in the perineurium. This is shown for the transplanted nerves in Figure 2, $a$ and $b$, at DPT 5 and 20. Highest numbers of endoneurial macrophages in the transplanted nerves were observed on DPT 10 , corresponding to day 15 after nerve transection. This increase in macrophage numbers was statistically significant $(p<0.05)$ when compared with the total number of endoneurial macrophages on DPT 2 and 5. The number of macrophages in the transplanted nerves then decreased significantly at DPT $20(p<$ 0.05 ) and did not change until DPT 40 (Fig. 3a). A similar time course of endoneurial macrophage infiltration was observed within the recipient nerves, although at a slightly lower level (Fig. $3 b)$. The number of endoneurial macrophages counted on days after transection 5-40 was significantly higher than those at day after transection $2(p<0.0005)$. Transected control nerves, which degenerated in the absence of any transplantation procedure, also revealed similar macrophage numbers (Fig. 3a,b). Within the perineurium of the nerves, slightly higher macrophage numbers were observed with a similar distribution in the different experimental groups (data not shown). Additionally, the perineurial inflammatory infiltrate of all transected nerves consisted of CD3positive T-cells and some granulocytes. At the end of the obser-

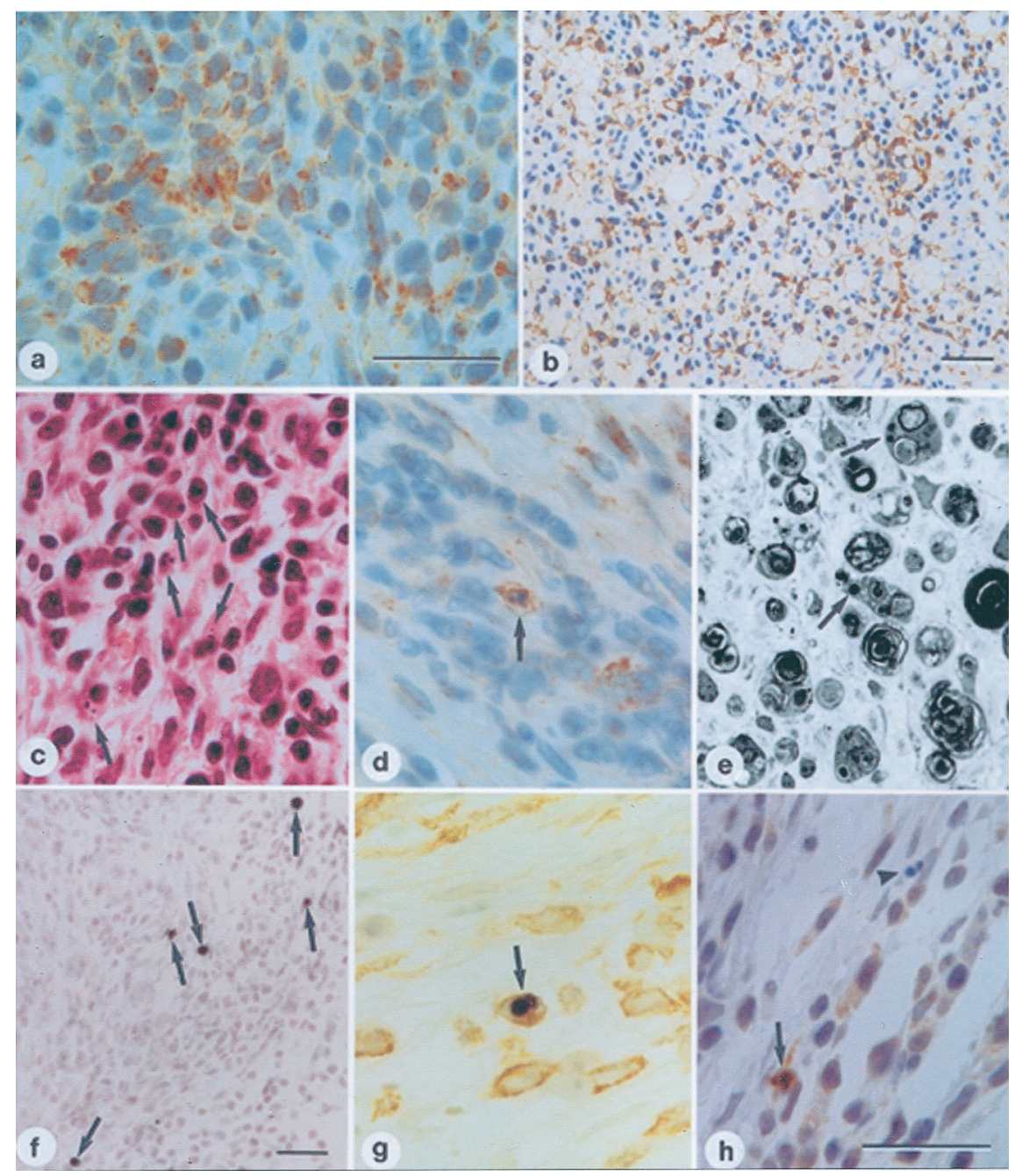

Figure 2. $a, b$, Numerous macrophages are present within the transplanted male sciatic nerve, as detected by immunocytochemistry for the Mac-3 (DPT 5) $(a)$ or F4/80 (DPT 20) (b) antigens. $c-h$, Detection of apoptotic macrophages within the transplanted male donor nerve. $c$, Morphologically, cells with the typical hallmarks of apoptosis (arrows) such as chromatin condensation and margination and apoptotic bodies are present (H\&E). $d$, Immunocytochemistry for Mac-3 shows an apoptotic macrophage (arrow) with a condensed and fragmented nucleus. $e$, Semithin section of sciatic nerve $10 \mathrm{~d}$ after transection. Myelin debris-containing macrophages with dark, condensed nuclei (arrows) typical for apoptosis are present. $f$, Detection of DNA fragmentation with the in situ tailing technique. Degenerating cells (arrows) are present within the transplanted nerve. $g$, Double staining for IST and F4/80 identifies a macrophage with DNA fragmentation (arrow). $h$, Immunocytochemistry for CM-1. CM-1-positive (arrow) and CM1-negative (arrowhead) cells with the typical morphology of apoptosis. Scale bars, $25 \mu \mathrm{m}$. 
Transplanted nerves

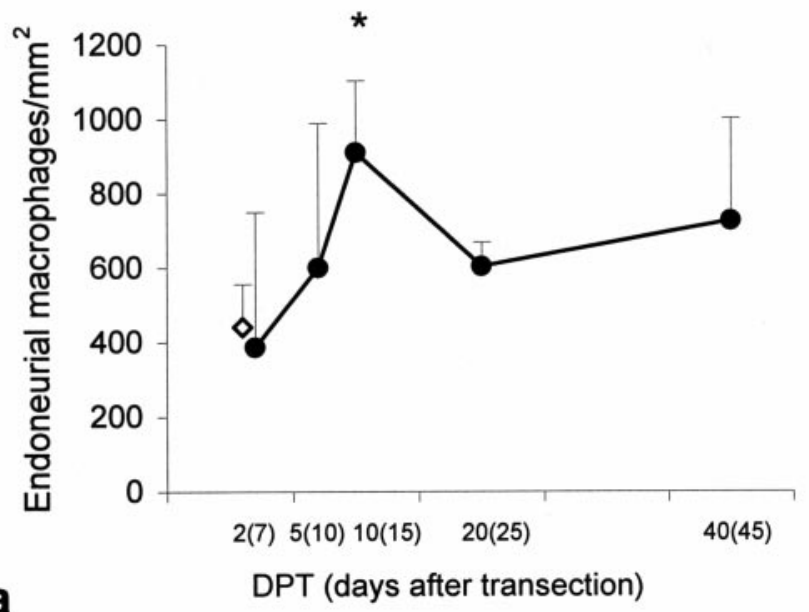

a

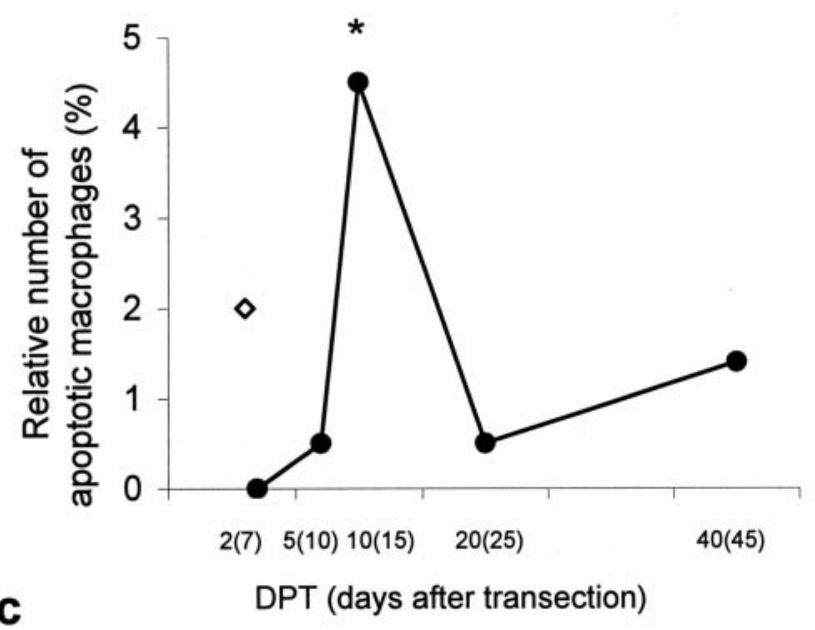

Recipient nerves
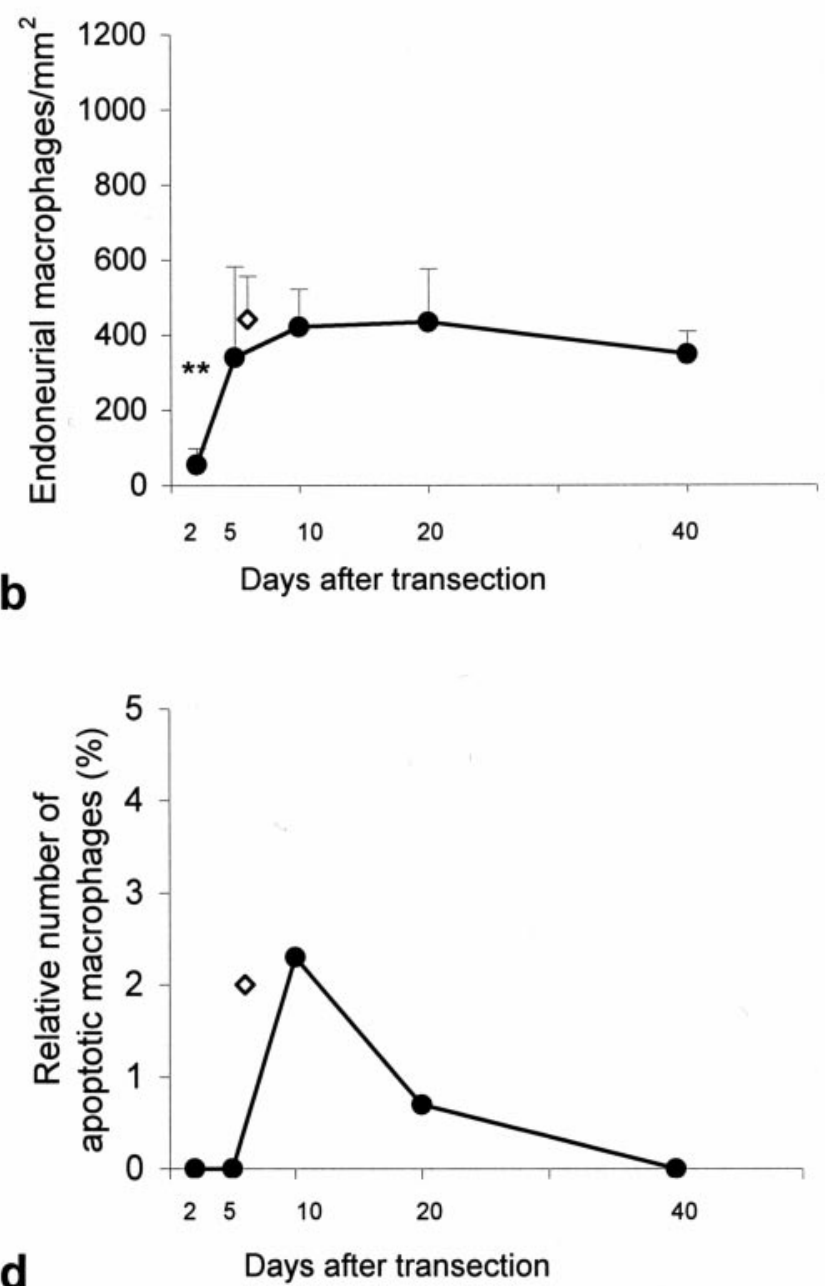

Figure 3. Quantitative data of invading $(a, b)$ and apoptotic $(c, d)$ macrophages in transplant $(a, c)$ and recipient nerves $(b, d)$. The open square represents cell numbers in the degenerating control nerve. *Statistically significant $(p<0.05)$ versus the total number of endoneurial macrophages at DPT 2 and 5 and DPT 20 as well as the relative number of apoptotic macrophages at the same time points. **Statistically significant $(p<0.0005)$ versus the number of endoneurial macrophages at all other time points.

vation periods, transplanted and recipient nerves were still aligned in most of the animals. However, nerve degradation especially in the transplanted nerve, was more advanced and did not allow exact measurement of nerve length at that time. This might be attributable to the lack of a continuous epineurial and perineurial nerve sheath that was still present in the distal degenerating nerve stump of the transected recipient nerves. However, this did not significantly affect cell invasion and macrophage apoptosis, as shown above and below.

\section{Detection of apoptotic cells within the transected nerves}

\section{Morphological criteria}

Endoneurial as well as perineurial cells with morphological criteria of apoptosis (nuclear and cytoplasmic condensation, margination of chromatin, formation of apoptotic bodies) were observed in the H\&E stains (Fig. 2c), both in the transplanted and recipient nerves as well as in control nerves. Apoptotic endoneurial macrophages were seen at all time points after transplantation. By using the macrophage marker Mac-3, a maximum of $41 \pm 35$ endoneurial macrophages $/ \mathrm{mm}^{2}$ revealed morphological signs of apoptosis on DPT 10 (corresponding to day 15 after transection) in the transplanted nerves, representing $4.5 \%$ of the entire endoneurial macrophage population (Fig. 3c). This increase of the number of apoptotic macrophages at DPT 10 was statistically significant $(p<0.05)$ when compared with the relative number of apoptotic macrophages at DPT 2 and 5 and DPT 20. In the recipient nerves, the highest numbers of apoptotic macrophages were observed on day 10 after transection (Fig. 3d). Apoptosis of macrophages was also regularly observed in control nerves degenerating for $6 \mathrm{~d}$. Thus, the presence of apoptotic macrophages seems to be a common phenomenon in nerves undergoing Wallerian degeneration and was not significantly affected by the transplantation procedure or the deprivation of the transplanted nerve from its distal ensheathed part. No major differences were seen in the number of apoptotic macrophages between the endoneurial and perineurial space (data not shown).

In additional experiments, control nerves were allowed to degenerate in situ for $10 \mathrm{~d}$. In semithin sections of these nerves, numerous macrophages were seen. Axons and myelin sheaths degenerated, and the infiltrating macrophages extensively in- 


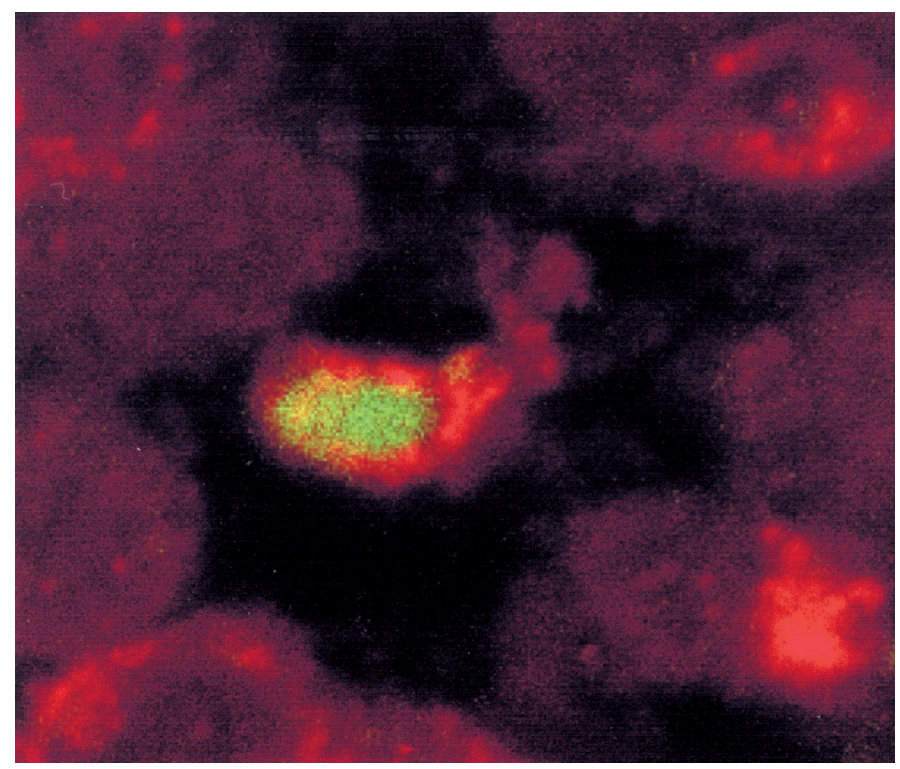

Figure 4. Double immunofluorescence for CM-1 (green) and Mac-3 (red). The double-labeled macrophage is clearly detected.

gested the myelin fragments. Some of these macrophages contained a condensed and fragmented nucleus, changes typical for apoptosis (Fig. 2e). Additionally, a few macrophages were observed containing apoptotic bodies in their cytoplasms, which possibly represents phagocytosis of apoptotic cells by macrophages.

\section{Detection of DNA fragmentation}

Numerous cells with signs of DNA fragmentation were identified by the IST technique. IST-positive cells were observed in the endoneurium of transplanted as well as recipient nerves at all time points investigated (Fig. $2 f$ ). Cells with DNA fragmentation were also detected within the control nerves. Double staining of IST and the macrophage-specific antigen F4/80 revealed a subpopulation of macrophages that were IST-positive (Fig. $2 g$ ). Similar numbers of IST-positive macrophages were seen in recipient and control nerves (data not shown).

\section{CM-1 antibody staining}

In our study, CM-1-positive cells were observed in the endoneurium in all transplanted nerves and in recipient nerves from day 10 after transection on. Few CM-1-negative cells with morphological signs of apoptosis were observed (Fig. $2 h$ ). The highest numbers of CM-1-positive cells in transplanted nerves were found on DPT 10 and in recipient nerves at day 10 after transection, thus corresponding to the numbers of apoptotic macrophages detected by morphological criteria as described above. The numbers of CM-1-positive cells were slightly lower than the number of cells identified morphologically or by DNA fragmentation. Double immunofluorescence staining clearly identified CM-1-positive macrophages (Fig. 4).

\section{Detection of 145SC5-positive cells by in situ hybridization}

In situ hybridization with the Y chromosome-specific 145SC5 probe revealed a strong signal within the transplanted male nerves (Fig. $5 a, b$ ), proving these cells to originate from the male donor animals. Numerous 145SC5-positive cells were seen at all time points after transplantation in the endoneurial and perineur- ial tissue of the transplanted nerve in all animals studied (Fig. $5 c, d$, Table 1). There were also $\mathrm{Y}$ chromosome-positive cells present in the female host nerve in 3 of 14 animals (Fig. 5e), indicating migration of these cells from the transplanted to the host nerve. The majority of the animals (13 of 14) revealed 145SC5-positive cells in the perivascular spaces (Fig. 5f) and sometimes also in regional lymph nodes (3 of 14 animals). Occasionally, Y chromosome-positive cells were seen closely attached to endothelial cells at the luminal surface of perineurial blood vessels (Fig. 5f), possibly indicating that these cells are in the process of crossing the endothelial cell layer. The presence of intraluminal cells is technically impossible to prove after perfusion of the animals. We also studied the presence of 145SC5expressing cells in para-aortal lymph nodes. In all mice, positive cells were observed in the lymph nodes (Fig. $5 g$ ) but not in the perivascular spaces of the aorta or its branches. The highest numbers of positive cells were observed on DPT 20. In 10 of 15 animals, positive cells were also detected within the red and white pulp as well as in the marginal zone of the spleen (Fig. $5 h$, Table 1).

To confirm the bidirectional migration of host and donor cells, we transplanted two female sciatic nerve fragments into two male mice. Also in the female nerve segments some 145SC5-positive cells were detected (data not shown), indicating that host cells invaded the transplanted donor nerve.

\section{DISCUSSION}

Traumatic injury of peripheral nerves results in characteristic changes designated as Wallerian degeneration. The phenomenon of Wallerian degeneration includes myelin and axon degeneration as well as the influx of macrophages from the circulation, which remove the degenerating nerve structures. Macrophages also seem to be engaged in the initiation of regeneration by producing growth factors (Perry et al., 1987). The fate of the macrophages within the degenerating nerve is still unknown. Taking into account knowledge from other models of tissue injury, it seems possible that these cells die locally within the nerves or that alternatively they reach the systemic circulation and are eliminated in the lymph nodes or the spleen. The present series of experiments provides evidence for both local apoptosis of macrophages within the injured nerves as well as migration of these cells to local lymph nodes and spleen.

Our study unequivocally identified local apoptosis within the degenerating nerves as one mechanism by which macrophages are eliminated from the injured peripheral nervous system. Apoptosis of macrophages was confirmed with similar results in three independent tissue samples, namely within degenerating control nerves as well as within the graft and recipient nerves of the transplantation experiments. Therefore, it seems unlikely that local macrophage apoptosis in transplanted nerves is induced by the transplantation procedure itself or by the disconnection of the transplanted nerve from its distal part. The apoptotic nature of cell death was confirmed in the present study not only by morphological criteria, but also by detection of DNA fragmentation and activated caspase-3. In concert, these three different methods represent reliable tools to demonstrate apoptosis. Alternatively, fluorescence-activated cell sorting (FACS) analysis of dissociated cells from the degenerating nerves and double staining with Mac-3 and propidium iodide could also identify apoptotic macrophages in the nerves. However, we did not consider this method to be valuable for our experiments because the typical morphology would be lost, and the sensitivity of the detection of DNA 
Figure 5. Detection of Y chromosome-positive cells. $a, \mathrm{H} \& \mathrm{E}$ stain showing the highly cellular transplanted nerve at the left margin and several fascicles of the host nerve at the right margin. $b$, The same nerve as shown in $a$ stained for the Y-chromosome probe 145SC5. There are numerous positive cells within the transplanted nerve and the surrounding perineurial tissue. $c$, High magnification of the grafted nerve showing numerous large, round $\mathrm{Y}$ chromosomepositive cells with macrophage morphology. $d$, Y chromosome-positive cells are also present in the surrounding perineurial tissue of the transplanted nerve. $e$, Few $\mathrm{Y}$ chromosome-positive cells are detected in the female host nerve. $f-h$, Y chromosome-positive cells $(f)$ closely attached to an endothelial cell at the luminal surface (arrow) of a perineurial blood vessel, $(g)$ in a para-aortal lymph node and $(h)$ in the spleen. Scale bars: $a, b, 100 \mu \mathrm{m} ; c-h, 25 \mu \mathrm{m}$.
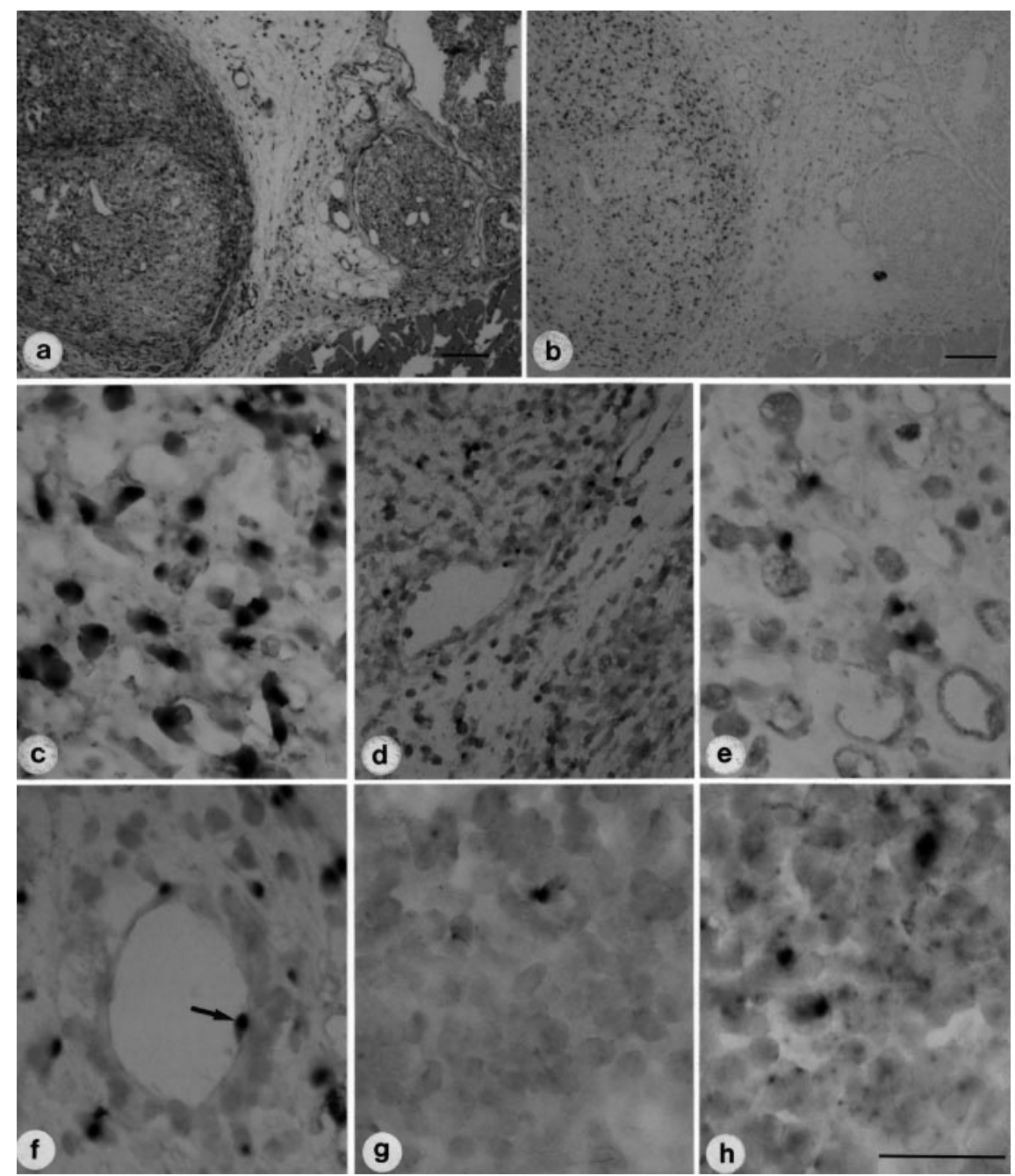

\section{Table 1. Detection of 145SC5-positive cells}

\begin{tabular}{|c|c|c|c|c|c|c|}
\hline $\mathrm{DPT}$ & Graft nerves & Recipient nerves & Perineurial tissue & $\begin{array}{l}\text { Regional lymph } \\
\text { nodes }^{a}\end{array}$ & $\begin{array}{l}\text { Paraaortal } \\
\text { lymph nodes }\end{array}$ & Spleen \\
\hline $2(n=3)$ & $+++/+++/+++$ & $+1-1-$ & $+++/+++/+++$ & $++1-1-$ & $+++/+++/+$ & $+++/+++/++$ \\
\hline $5(n=3)$ & $+++/+++/+++$ & $+1-1-$ & $+++/+++/+++$ & $-1-1-$ & $+/+/+$ & $+++/-/+$ \\
\hline $10(n=3)$ & $+++/+++/+++$ & $+1-1-$ & $+++/+++/+++$ & $-1-1-$ & $++/++/+$ & $+++/++1-$ \\
\hline $20(n=3)$ & $+++/+++/+++$ & $-1-1-$ & $+++/+++/+++$ & $+++1-1-$ & $+/+++/++$ & $+++/-1+$ \\
\hline $40(n=2)$ & $+++/+++$ & $-1-$ & $+++/+++$ & $+1-$ & $+/+$ & $+++/-$ \\
\hline
\end{tabular}

DPT, Days after transplantation; +++, more than 10145 SC5 positive cells, ++ , between 5 and 10 positive cells, + , between 1 and 4 positive cells.

${ }^{a}$ Regional lymph nodes were only seen in three animals with the presence of 145SC5-positive cells in each of them.

fragmentation and activated caspase-3 would be compromised using the FACS method.

Apoptosis is an active process characterized by nuclear and cytoplasmic condensation and disintegration of the cell into membrane-bound fragments, so called apoptotic bodies (Lo et al., 1995). Additionally, activated caspase-3 is considered to be a central apoptotic effector enzyme in many experimental paradigms, located beyond the point of no return in the cell death program. Cells with prominent activation of caspase-3 are prone to die (Srinivasan et al., 1998; Thornberry and Lazebnik, 1998). Initiation of the caspase cascade finally leads to the cleavage of proteins critical for cell survival and to the activation of endonucleases resulting in DNA fragmentation (Thornberry and La- zebnik, 1998). In transected nerves, we detected higher numbers of cells with signs of DNA fragmentation than clearly apoptotic cells. This may be attributable to the fact that DNA fragmentation can be also found in necrotic cells (Grasl-Kraupp et al., 1995). Techniques that detect DNA strand breaks can therefore not be considered specific for apoptotic cell death, and this may explain our findings.

The low numbers of apoptotic macrophages in transected peripheral nerves are in accordance with results obtained in experimental autoimmune encephalomyelitis (EAE), in which also only few apoptotic macrophages were detected (Nguyen et al., 1994, 1997; Smith et al., 1996; White et al., 1998). The ineffective elimination of macrophages from the nervous system may finally 
lead to the known long-term accumulation of macrophages in the perivascular spaces after CNS injury (Kösel et al., 1997; Nguyen et al., 1997). The reasons for the relatively low rate of macrophage apoptosis as well as the exact mechanisms that regulate this process are still unclear. A very simple explanation might be the fact that the morphologically visible stages of apoptosis require only $\sim 4 \mathrm{hr}$ for completion, and therefore only few apoptotic cells are observed at a single time point (Bursch et al., 1990; GraslKraupp et al., 1995). It is known, however, that macrophages are relatively resistant to apoptosis compared with monocytes. A possible explanation is the upregulation of Flip (FLICE inhibitory protein), which blocks the FAS-mediated apoptotic pathway (Perlman et al., 1999). It was also shown that activation of monocytes results in an increased resistance to apoptosis associated with a downregulation of caspase- 8 and an increased expression of the Bfl-gene, an antiapoptotic member of the bcl-2 family (Perera and Waldmann, 1998). In addition to Fas/FasL, an induction of apoptosis through TRAIL- and TWEAK-mediated pathways has been described (Kaplan et al., 2000). In vitro experiments have demonstrated that the apoptotic cell death of macrophages is regulated by activation of caspases 3 and 8 (Fahy et al., 1999). In our experiments, the number of cells positive for CM-1, an antibody against activated caspase-3, was generally lower compared with the number of cells with morphological characteristics of apoptosis. In fact, some apoptotic but CM-1negative cells were seen, indicating that CM-1 does not detect all stages of programmed cell death, as described earlier (Stadelmann et al., 1999) or that some cells may less likely undergo a caspase-independent apoptotic pathway (Susin et al., 1999).

Our data suggest that the systemic elimination of macrophages via lymph nodes and spleen is involved in macrophage disappearance from the injured peripheral nerve. We demonstrate that macrophages from the transplanted nerve also invaded the recipient nerve and vice versa. A Y-chromosome-specific DNA probe was used to follow transplanted cells on their way through the host organism. This tool has been shown to be a reliable marker for transplanted cell populations in different experimental models (Singh et al., 1987; Hampson et al., 1989; Grounds et al., 1991; Hagenaars et al., 1994; Singh et al., 1994; Harvey et al., 1997). Our data suggest a direct migration of macrophages between the transplanted and recipient nerves without passing through the circulation. The question whether macrophages that leave the transplanted nerve and enter the bloodstream then reenter an area of nerve damage remains open and could only be answered under the condition when the host nerve is crushed but not cut. However, it is not known whether the degenerative process in crushed nerves occurs differently from that in cut nerves; it should be assumed that macrophage migration into a crushed nerve is slower than into a transected nerve. To ascertain similar experimental conditions for both, the transplanted and the recipient nerve, we decided to use the transection model for both nerves.

In our experiments, we detected 145SC5-positive cells at all time points after transplantation (2-40 d) within the spleen and lymph nodes, indicating active migration via lymphatic and blood vessels. There is little knowledge on the migration of macrophages from the periphery to lymphatic organs. Macrophages injected in the splenic artery reach the splenic parenchyma within few minutes and remain there for at least $36 \mathrm{hr}$ (Miyakawa et al., 1990). Directed migration of cells is generally regulated by a group of molecules designated as chemokines. These chemokines belong to different families, attract different leukocyte subpopulations, and are ligands for specific receptors (Baggiolini et al.,
1994, 1997; Raport et al., 1996; Rollins, 1997). We and others have demonstrated a crucial role for the chemokine MCP-1 and its receptor CCR2 during macrophage recruitment into transected peripheral nerves (Toews et al., 1998; Siebert et al., 2000). Furthermore, a critical role for the chemokine receptor CCR-7 on dendritic cells has been shown in the migration from tumor sites to draining lymph nodes, especially after interaction with apoptotic tumor cells (Hirao et al., 2000). Similar mechanisms could play a role in our experimental model when macrophages move to the lymph nodes and spleen. Several other factors such as state of maturation, tissue origin, matrix structure, and proinflammatory cytokines have been shown to be involved in the migration of dendritic cells within collagen lattices (Gunzer et al., 2000).

The local and systemic elimination of myelin-laden macrophages may also have implications for the development of subsequent autoimmune disorders. Thus, the migration of myelinpresenting macrophages to lymph nodes and the spleen raises the possibility of the induction of an autoimmune process. In general, Wallerian degeneration in the nervous system is not followed by an autoimmune attack (Wekerle et al., 1986). However, in animal models it has been shown that traumatic lesions may predispose the nervous tissue for developing inflammatory autoimmune reactions (Maehlen et al., 1989; Konno et al., 1990).

In conclusion, the present data indicate that two mechanisms are involved in the disappearance of macrophages from the damaged peripheral nerve: local apoptosis and immigration into the lymph nodes and spleen. Systemic elimination via lymph nodes and spleen is a process that requires active and directed migration of the cells. Further experiments have to clarify the exact mechanisms leading to macrophage apoptosis as well as the molecular signals involved in the directed migration of macrophages to lymphatic organs.

\section{REFERENCES}

Baggiolini M, Dewald B, Moser B (1994) Interleukin-8 and related chemotactic cytokines-CXC and $\mathrm{CC}$ chemokines. Adv Immunol 55:97-179.

Baggiolini M, Dewald B, Moser B (1997) Human chemokines: an update. Annu Rev Immunol 15:675-705.

Barth MW, Hendrzak JA, Melnicoff MJ, Morahan PS (1995) Review of the macrophage disappearance reaction. J Leukoc Biol 57:361-367.

Beuche W, Friede RL (1984) The role of non-resident cells in Wallerian degeneration. J Neurocytol 13:767-796.

Breitschopf H, Suchanek G, Gould RM, Colman DR, Lassmann H (1992) In situ hybridization with digoxigenin-labeled probes: sensitive and reliable detection method applied to myelinating rat brain. Acta Neuropathol 84:581-587.

Brown HC, Castano A, Feam S, Townsend M, Edwards G, Streuli C, Perry VH (1997) Adhesion molecules involved in macrophage responses to Wallerian degeneration in the murine peripheral nervous system. Eur J Neurosci 9:2057-2063.

Brück W (1997) The role of macrophages in Wallerian degeneration. Brain Pathol 7:741-752.

Brück W, Friede RL (1990) Anti-macrophage CR3 antibody blocks myelin phagocytosis by macrophages in vitro. Acta Neuropathol 80:415-418.

Brück W, Friede RL (1991). The role of complement in myelin phagocytosis during PNS Wallerian degeneration. J Neurol Sci 103:182-187.

Brück W, Brück Y, Maruschak B, Friede RL (1995) Mechanisms of macrophage recruitment in Wallerian degeneration. Acta Neuropathol 89:363-367.

Brück W, Huitinga I, Dijkstra CD (1996a) Liposome-mediated monocyte depletion during Wallerian degeneration defines the role of hematogenous phagocytes in myelin removal. J Neurosci Res 46:477-484.

Brück Y, Brück W, Kretzschmar HA, Lassmann H (1996b) Evidence for neuronal apoptosis in pontosubicular neuron necrosis. Neuropathol Appl Neurobiol 22:23-29.

Bursch W, Paffe S, Putz B, Barthel G, Schulte-Hermann R (1990) Determination of the length of the histological stages of apoptosis in normal liver and in altered hepatic foci of rats. Carcinogenesis 11:847-853. 
Fahy RJ, Doseff AI, Wewers MD (1999) Spontaneous human monocyte apoptosis utilizes a caspase-3-dependent pathway that is blocked by endotoxin and is independent of caspase-1. J Immunol 163:1755-1762.

Fernandez-Valle C, Bunge RP, Bunge BM (1995) Schwann cells degrade myelin and proliferate in the absence of macrophages: evidence from in vitro studies of Wallerian degeneration. J Neurocytol 24:667-679.

George EB, Glass JD, Griffin JW (1995) Axotomy-induced axonal degeneration is mediated by calcium influx through ion-specific channels. J Neurosci 15:6445-6452.

Gold R, Schmied M, Rothe G, Zischler H, Breitschopf H, Wekerle H, Lassmann H (1993) Detection of DNA fragmentation in apoptosis: application of in situ nick translation to cell culture systems and tissue sections. J Histochem Cytochem 41:1023-1030.

Grasl-Kraupp B, Ruttkay-Nedecky B, Koudelka H, Bukowkska K, Bursch W, Schulte-Herrmann R (1995) In situ detection of fragmented DNA (TUNEL assay) fails to discriminate among apoptosis, necrosis and autolytic cell death: a cautionary note. Hepatology 21:1465-1468.

Griffin JW, Hoffman PN (1993) Degeneration and regeneration in the peripheral nervous system. In: Peripheral neuropathy (van Dyck PJ, Thomas PK, Griffin JW, Low PA, Poduslo JF, eds), pp 361-376. Philadelphia: W.B. Saunders.

Griffin JW, George R, Lobato C, Tyor WR, Yan LC, Glass JD (1992) Macrophage responses and myelin clearance during Wallerian degeneration: relevance to immune-mediated demyelination. J Neuroimmunol 40:153-166.

Grounds MD, Lai MC, Fan Y, Codling JC, Beilharz MW (1991) Transplantation in the mouse model - the use of a Y-chromosome-specific DNA clone to identify donor cells in situ. Transplantation 52:1101-1105.

Gunzer M, Friedl P, Niggemann B, Bröcker E-B, Kämpgen E, Zänker KS (2000) Migration of dendritic cells within 3-D collagen lattices is dependent on tissue origin, state of maturation, and matrix structure and is maintained by proinflammatory cytokines. J Leukoc Biol 67:622-629.

Hagenaars CE, Kawilarang-de Haas EWM, Hazekamp J, Wiegant J, Nijweide PJ (1994) Osteoclast development in the coculture system of periostless metatarsal bones and hemopoietic cells studied by in situ hybridization with a probe for $\mathrm{Y}$ chromosomes. Calcif Tissue Int 54:170-174.

Hampson IN, Spooncer E, Dexter TM (1989) Evaluation of a mouse Y chromosome probe for assessing marrow transplantation. Exp Hematol 17:313-315.

Harvey AR, Symons NA, Pollett MA, Brooker GJF, Bartlett PF (1997) Fate of adult neural precursors grafted to adult cortex monitored with a Y-chromosome marker. NeuroReport 8:3939-3943.

Hirao M, Onai N, Hiroishi K, Watkins SC, Matsushima K, Robbins PD, Lotze MT, Tahara H (2000) CC chemokine receptor-7 on dendritic cells is induced after interaction with apoptotic tumor cells: critical role in migration from the tumor site to draining lymph nodes. Cancer Res 60:2209-2217.

Kaplan MJ, Ray D, Mo R-R, Yung RL, Richardson BC (2000) TRAIL (Apo2 ligand) and TWEAK (Apo3 ligand) mediate CD $4^{+} \mathrm{T}$ cell killing of antigen-presenting macrophages. J Immunol 164:2897-2904.

Konno H, Yamamoto T, Suzuki H, Iwasaki Y, Ohara Y, Terunuma H, Harata N (1990) Targeting of adoptively transferred experimental allergic encephalitis lesion at the sites of Wallerian degeneration. Acta Neuropathol 80:521-526.

Kösel S, Egensberger R, Bise K, Arbogast S, Mehraein P, Graeber MB (1997) Long-lasting perivascular accumulation of major histocompatibility complex class II positive lipophages in the spinal cord of stroke patients: possible relevance for the immune privilege of the brain. Acta Neuropathol 94:532-538.

Lo AC, Houenou LJ, Oppenheim RW (1995) Apoptosis in the nervous system: morphological features, methods, pathology, and prevention. Arch Histol Cytol 58:139-149.

Maehlen J, Olsson T, Zachau A, Klareskog L, Kristensson K (1989) Local enhancement of major histocompatibility complex (MHC) class $\mathrm{I}$ and II expression and cell infiltration in experimental allergic encephalomyelitis around axotomized motor neurons. J Neuroimmunol 23:125-132.

Miyakawa K, Matsuno K, Ohmori J, Kotani M (1990) Localization in the rat spleen of carbon-laden macrophages introduced into the splenic artery: a subpopulation of macrophages entering the white pulp. Anat Rec 227:464-474.

Nguyen KB, McCombe PA, Pender MP (1994) Macrophage apoptosis in the central nervous system in experimental autoimmune encephalomyelitis. J Autoimmun 7:145-152.

Nguyen KB, McCombe PA, Pender MP (1997) Increased apoptosis of T-lymphocytes and macrophages in the central and peripheral nervous system of Lewis rats with experimental autoimmune encephalomyelitis treated with dexamethasone. J Neuropathol Exp Neurol 56:58-69.

Perera LP, Waldmann TA (1998) Activation of human monocytes induces differential resistance to apoptosis with rapid down-regulation of caspase-8/FLICE. Proc Natl Acad Sci USA 95:14308-14313.

Perlman H, Pagliari LJ, Georganas C, Mano T, Walsh K, Pope RM (1999) FLICE-inhibitory protein expression during macrophage differentiation confers resistance to Fas-mediated apoptosis. J Exp Med 190:1679-1688.

Perry VH, Brown MC, Gordon S (1987) The macrophage response to central and peripheral nerve injury. A possible role for macrophages in regeneration. J Exp Med 165:1218-1223.

Raport CJ, Schweickart VL, Chantry D, Eddy RL Jr, Shows TB, Godiska R, Gray PW (1996) New members of the chemokine receptor gene family. J Leukoc Biol 59:18-23.

Rollins BJ (1997) Chemokines. Blood 90:909-928.

Sambrook J, Fritsch EF, Maniatis T (1989) Molecular cloning. A laboratory manual. Cold Spring Harbor Laboratory Press.

Shinohara S, Sawada T, Nishioka Y, Tohma S, Kisaki T, Inoue T, Ando K, Ikeda M, Fujii H, Ito K (1995) Differential expression of Fas antigen and bcl-2 protein on CD4 $+\mathrm{T}$ cells, CD8 + T cells, and monocytes. Cell Immunol 163:303-308.

Siebert H, Sachse A, Kuziel WA, Maeda N, Brück W (2000) The chemokine receptor CCR2 is involved in macrophage recruitment to the injured peripheral nervous system. J Neuroimmunol 110:177-185.

Singh L, Matsukuma S, Jones KW (1987) The use of Y-chromosomespecific repeated DNA sequences in the analysis of testis development in an XX/XY mouse. Development 101S:143-149.

Singh L, Panicker SG, Nagaraj R, Majumdar KC (1994) Banded krait minor-satellite $(\mathrm{Bkm})$-associated $\mathrm{Y}$ chromosome-specific repetitive DNA in mouse. Nucleic Acids Res 22:2289-2295.

Smith T, Schmied M, Hewson AK, Lassmann H, Cuzner ML (1996) Apoptosis of T cells and macrophages in the central nervous system of intact and adrenalectomized Lewis rats during experimental allergic encephalomyelitis. J Autoimmun 9:167-174.

Srinivasan A, Roth KA, Sayers RO, Shindler KS, Wong AM, Fritz LC, Tomaselli KJ (1998) In situ immunodetection of activated caspase-3 in apoptotic neurons in the developing nervous system. Cell Death Differ 5:1004-1016.

Stadelmann C, Deckwerth TL, Srinivasan A, Bancher C, Brück W, Jellinger K, Lassmann H (1999) Activation of caspase-3 in single neurons and autophagic vacuoles of granulovacuolar degeneration in Alzheimer's disease. Evidence for apoptotic cell death. Am J Pathol 155:1459-1466

Stoll G, Hartung H-P (1992) The role of macrophages in degeneration and immune-mediated demyelination of the peripheral nervous system. Adv Neuroimmunol 2:163-179.

Stoll G, Griffin JW, Li CY, Trapp BD (1989) Wallerian degeneration in the peripheral nervous system: participation of both Schwann cells and macrophages in myelin degradation. J Neurocytol 18:671-683.

Susin SA, Lorenzo HK, Zamzami N, Marzo I, Snow BE, Brothers GM, Mangion J, Jacotot E, Constantini P, Loeffler M, Larochette N, Goodlett DR, Aebersold R, Siderovski DP, Penninger JM, Kroemer G (1999) Molecular characterization of mitochondrial apoptosisinducing factor. Nature 397:441-446.

Takemura G, Ohno M, Hayakawa Y, Misao J, Kanoh M, Ohno A, Uno Y, Minatoguchi S, Fujiwara T, Fujiwara H (1998) Role of apoptosis in the disappearance of infiltrated and proliferated interstitial cells after myocardial infarction. Circ Res 82:1130-1138.

Thornberry NA, Lazebnik Y (1998) Caspases: enemies within. Science 281:1312-1316.

Toews AD, Barrett C, Morell P (1998) Monocyte chemoattractant protein 1 is responsible for macrophage recruitment following injury to sciatic nerve. J Neurosci Res 53:260-267.

Vougioukas VI, Roeske S, Michel U, Brück W (1998) Wallerian degeneration in ICAM-1-deficient mice. Am J Pathol 152:241-249.

Wekerle H, Linington C, Lassmann H, Meyermann R (1986) Cellular immune reactivity within the CNS. Trends Neurosci 9:271-277.

White CA, McCombe PA, Pender MP (1998) Microglia are more susceptible than macrophages to apoptosis in the central nervous system in experimental autoimmune encephalomyelitis through a mechanism not involving Fas (CD95). Int Immunol 10:935-941. 